\title{
Classes sociais e classes socioeconômicas: um estudo sobre os estratos sociais na Região Metropolitana de Salvador entre 2003 a 2010
}

\author{
Ualace Roberto de Jesus Oliveira ${ }^{1}$
}

1 Mestre em Economia pela Universidade Federal da Bahia (UFBA), Brasil. E-mail: ualacejesus@bol.com.br

RESUMO: No recente contexto das importantes mudanças sociais ocorridas no Brasil, a Região Metropolitana de Salvador (RMS) - que historicamente é conhecida pelos seus graves problemas socioeconômicos - logrou melhoria significativa em muitos aspectos sócio-ocupacionais. Porém, observa-se que a mobilidade social ocorrida entre as classes sociais na referida região foi pouco expressiva entre 2003 e 2010. Diante do exposto, o objetivo deste trabalho é observar por meio de uma abordagem descritiva a emergência de uma Nova Classe $C$ na RMS. Para tanto, será feita uma análise a partir de banco de dados da Pesquisa de Emprego e Desemprego do Dieese para os anos de 2003 e 2010. A metodologia a ser utilizada consiste num estudo descritivo. Os resultados nos mostram que embora muitos aspectos relacionados aos rendimentos do trabalho das famílias da base da pirâmide na RMS melhoraram o processo ocorrido na referida região não pode ser considerando como um movimento pleno de mudanças na estrutura social.

\section{Social classes and socioeconomic classes: a study on social strategies in the metropolitan re- gion of Salvador between 2003 and 2010}

ABSTRACT: In the recent context of important social changes in Brazil, the Metropolitan Region of Salvador (RMS) - which has historically been known for its serious socioeconomic problems - has achieved significant improvement in many socio-occupational aspects. However, it can be observed that social mobility between social classes in this region was not very significant between 2003 and 2010. In view of the above, the objective of this work is to observe through a descriptive approach the emergence of a New Class C in RMS. To do so, an analysis will be made from the database of the Dieese Employment and Unemployment Survey for the years 2003 and 2010. The methodology to be used is a descriptive study. The results show that although many aspects related to the income of the work of the families of the base of the $p$ yramid in RMS improved the process occurred in that region can not be considered as a full movement of changes in the social structure.

\section{INTRODUÇÃO}

As transformações que a economia brasileira vivenciou nas últimas décadas impactaram a estrutura social das regiões metropolitanas do país. Os impactos dessas transformações se deram, principalmente, nas regiões metropolitanas que haviam se industrializado na segunda metade do século $X X$. Nesse processo, cada região metropolitana se insere em contextos regionais parti- culares, onde as características socioeconômicas das unidades federativas em que elas se localizam podem exercer diferenças significativas entre as regiões metropolitanas. Na Região Metropolitana de Salvador (RMS), esta que está situada no Nordeste do país, notadamente na Bahia, as transformações pelas quais passou o Brasil na primeira década do século XXI trouxe um impacto importante na sua estrutura social. Os dados de pesquisas referentes à ocupa- 
ção da força de trabalho da população economicamente ativa, por exemplo, mostram que ocorreu importante expansão do emprego formal na RMS nessa década, muito embora parte significativa das vagas geradas tenha ocorrido em atividades que requeria apenas baixa ou nenhuma qualificação técnica. A despeito desses avanços, a referida região ainda conserva alguns estigmas sociais de um recente passado, tais como, elevado nível de desemprego, concentração de renda e expressivo contingente populacional que ainda vive em condições subumanas.

Diante do que foi exposto, o problema da presente pesquisa consiste em responder: As mudanças socioeconômicas ocorridas na RMS contribuíram para provocar um processo significativo de mobilidade social no seio da base da sua pirâmide social?

Esse trabalho se justifica com intuito de entender o fenômeno de mobilidade social no Brasil e, sobretudo, na Região Metropolitana de Salvador. No debate concernente às classes socioeconômicas na referida região, a análise de elementos sócio-ocupacionais, tais como: nível de escolaridade dos chefes de família, renda total das famílias, dentre outros, é de suma importância para compreender o fenômeno da mobilidade social.

Com a finalidade de alcançar os objetivos do trabalho, realizou-se uma análise a partir do banco de dados da Pesquisa de Emprego e Desemprego (PED) disponibilizados pela SEI/DIEESE para os de 2003 e 2010. A metodologia utilizada consistiu num estudo descritivo.

\section{METODOLOGIA E DADOS}

\subsection{Caracterização da pesquisa}

Estação Científica (UNIFAP)

ISSN 2179-1902
Com o objetivo de compreender melhor o tema referente a classes socioeconômicas, optou-se em realizar uma pesquisa descritiva. As pesquisas descritivas têm como principal objetivo descrever determinada população ou fenômeno, ou então, o estabelecimento de relações entre as variáveis, além de estudar as características de grupos sociais, tais como: nível de escolaridade, aspectos familiares, posição social, sexo, dentre outros ( $\underline{\mathrm{GI} L, 2008)}$ ).

\subsection{Aspectos metodológicos}

No âmbito das metodologias concernente às classes socioeconômicas, podem ser identificados dois vetores investigativos principais. O primeiro deles, mais utilizado em função da sua simplicidade, é o da medição da classe média a partir da renda individual ou familiar auferida a partir de faixas de renda, que geralmente estabelecem de modo arbitrário os parâmetros inferiores e superiores (LANGONI, 1973 apud GUERRA et $a l, 2006)$. Desse modo, são obtidos os critérios que normalmente são utilizados em pesquisas de opinião pública ou de consumo, tais como as classes A, B, C, D e E, por exemplo. Trata-se simplesmente de uma subdivisão efetuada no interior da pirâmide distributiva de cada país (GUERRA et al, 2006).

O segundo vetor investigativo se detém mais na compreensão da classe média, a partir dos indivíduos em função de critérios sócio-ocupacionais (GUERRA et al, 2006). Dessa forma, ao contrário da definição de classe média baseada no critério de diferencial de rendimento ou participação na renda nacional, há uma possibilidade concreta de perceber a manifestação de distintas trajetórias ocupacionais que delimitam a 
classe média, bem como a dinâmica de sua manifestação ao longo do tempo. Nesse vetor investigativo, há também uma segunda dimensão metodológica que possibilita o tratamento da estrutura ocupacional familiar e não somente de critérios sócioocupacionais. Em conformidade com a divisão do trabalho em cada espaço territorial, pode-se chegar à constituição dos segmentos sociais identificados como classe média. Nesse processo a estrutura sócio-ocupacional, por estar diretamente relacionada à divisão do trabalho, sofre as consequências decorrentes das transformações sociais na dinâmica capitalista.

Para o presente trabalho, julga-se mais adequado utilizarmos o critério que estratifica as classes socioeconômicas na Região Metropolitana de Salvador pela renda mensal familiar. Os anos escolhidos para tanto foram os anos Governo Lula (2003 a 2010), haja vista ser considerado um divisor de águas na história recente do Brasil, pois nesse período, como já foi dito outrora, observou-se uma progressiva reativação do mercado de trabalho formal associado à melhoria das oportunidades de negócios, por exemplo.

Para melhor compreendermos as mudanças ocorridas na estrutura social da RMS, utilizamos a metodologia comumente empregada pelo Instituto Brasileiro de Geografia e Estatística (IBGE), que estratifica as classes com base na renda familiar auferida em termos de salário mínimo. Não obstante, consideraremos as classes A, B, C, D e E, como sendo, respectivamente, a classe alta, média, batalhadora, pobre e a ralé (Quadro 1), de modo a termos uma abordagem sociológica e mais crítica. Desse modo temos:
Quadro 1 - Faixas de renda

Frame 1 - Income brackets

\begin{tabular}{|c|c|}
\hline Classes sociais & $\begin{array}{c}\text { Número de Salários Míni- } \\
\text { mos }\end{array}$ \\
\hline Classe alta (classe A) & Acima de 20 SM \\
\hline Classe média (classe B) & 10 a 20 SM \\
\hline Batalhadores (classe C) & 4 a 10 SM \\
\hline Pobres (classe D) & 2 a 4 SM \\
\hline Ralé (classe E) & Até 2 SM \\
\hline
\end{tabular}

Fonte: Elaboração própria, com base no IBGE, 2015

Vale ressaltar que a distribuição dos ocupados por faixas de rendimentos em salários mínimos fornece elementos para compreender as transformações em curso no mercado de trabalho metropolitano além das condições sócio-ocupacionais das famílias nas suas respectivas classes sociais.

\subsection{Base de dados}

A Pesquisa do Emprego e Desemprego (PED) do Dieese tem como unidade amostral o domicílio da área urbana que a compõem. A metodologia de sorteio produz uma amostra equiproporcional em dois estágios, sendo os setores censitários sorteados dentro de cada zona de interpolação e os domicílios dentro de cada setor censitário. Estes municípios estão subdivididos em 17 distritos, 22 subdistritos, 165 zonas de informação e 2.243 setores censitários. A pesquisa coletou informações mensalmente, através de entrevistas com moradores, em 2.500 domicílios da Região Metropolitana de Salvador, resultando na aplicação de cerca de 9.000 questionários/mês. Ao contrário de outras pesquisas, sua metodologia, ao privilegiar a condição de procura de trabalho, na caracterização da situação ocupacional dos indivíduos, permite captar formas de desemprego que são próprias de mercados de trabalho estruturalmente heterogêneos, como é o caso do brasileiro e por extensão da RMS (DIEESE, 2012) 
Em cada unidade domiciliar amostrada, foram pesquisados - por meio de entrevistas diretamente realizadas - todos os indivíduos residentes, independentemente da sua posição no domicílio. Os dados inicialmente são sujeitos a um processo de verificação cuidadoso que envolve a checagem de uma amostra de $20 \%$ do número total de domicílios realizados, além da verificação, caso a caso, de todos aqueles que apresentavam problemas em qualquer das etapas de crítica dos questionários. O questionário se estrutura, para fim de recuperação da informação, em três grandes partes que funcionam como subarquivos independentes, mas relacionáveis. A primeira sintetiza características gerais do domicílio pesquisado (como localização, número de membros, de famílias, sexo dos membros e identificação dos maiores e menores de 10 anos). A segunda apresenta as características individuais de todos os menores de 10 anos presentes nos domicílios (como idade, escolaridade, condição migratória, posição na família e domicílios). A terceira faz o mesmo para a População em Idade Ativa; ademais, no que diz respeito à População em Idade Ativa o questionário se desdobra numa longa e rica série de perguntas que abre um enorme elenco de alternativas para o estudo da ocupação (segundo setor de atividade, tamanho da empresa, localização desta, ocupação, posição na ocupação, horas trabalhadas, etc.) e do desemprego (em múltiplas formas: desemprego aberto, oculto pelo trabalho precário e pelo desalento, novidades de mensuração introduzidas pela metodologia do Dieese). Tal como desenhado, o questionário oferece grandes possibilidades para análise do emprego e desemprego na sua relação com a procura de trabalho (CASTRO; BARRETO, 1998).
Ademais, a PED julga que é preciso qualificar e ampliar esses conceitos para que alcancem a captação não só das situações claramente definidas de ocupação e desemprego, mas também daqueles intermediários que as pesquisas tradicionais desconsideram e incluem nas condições de inatividade ou de ocupação. Ao definir os conceitos de trabalho e de desemprego, a PED reelaborou as definições de ocupados e desempregados e por conseqüência, as de população economicamente ativa e de população inativa. Nesse processo, há algumas variáveis utilizadas pela PED que, inclusive, foram incorporadas ao presente trabalho que estão abaixo explicitadas conforme Dieese (2012):

- Ocupados - São os indivíduos que, nos sete dias anteriores ao da entrevista, possuem trabalho remunerado exercido regularmente, com ou sem procura de trabalho; ou que, neste período, possuem trabalho remunerado exercido de forma irregular, desde que não tenham procurado trabalho diferente do atual; ou possuem trabalho não-remunerado de ajuda em negócios de parentes, ou remunerado em espécie/benefício, sem procura de trabalho. Excluem-se as pessoas que nos últimos sete dias realizaram algum trabalho de forma excepcional.

- Família - Conjunto de pessoas residentes em um domicílio ligadas por laços de parentesco (consanguinidade, adoção ou afinidade), podendo ainda ser integrado por outros indivíduos não parentes entre si, assim como a pessoa que vive só ou qualquer grupo de no máximo cinco pessoas não aparentadas que residem no mesmo domicílio. A identificação de uma ou mais famílias em um domicílio é obtida a partir da ordenação das relações nucleares (ca- 
sal), relações primárias (pai, mãe, filho, irmão) e relações secundárias (tio, sobrinho, primo, etc.).

- Inativos (de dez anos e mais) - Parcela da População em Idade Ativa que não está ocupada ou desempregada. Incluem-se as pessoas sem procura de trabalho que, nos últimos 30 dias, realizaram algum trabaIho de forma excepcional porque lhes sobrou tempo de seus afazeres principais.

- Posição no Domicílio e na Família: Cada indivíduo possui uma posição no domicílio ou na família, segundo sua relação com o chefe do domicílio e da família: 1) chefe do domicílio e da família: morador (homem ou mulher) considerado pelos demais como o responsável pelo domicílio (ou pela família); 2) cônjuge: morador que vive conjugalmente com o chefe, independentemente do reconhecimento legal deste vínculo; 3) filho: morador(a) filho(a), filho(a) adotivo(a), enteado(a) ou de criação do chefe e/ou do seu cônjuge; 4) outro parente: morador com algum laço de parentesco com o chefe ou com seu cônjuge; 5) agregado: morador que não é parente do chefe ou do seu cônjuge e que não paga pensão; 6) pensionista: morador não parente que paga hospedagem; 7) empregado doméstico: morador que presta serviços de forma remunerada à família do chefe e que dorme no domicílio; 8) parente do empregado doméstico: morador que tem laços de parentesco com o empregado doméstico e que não presta serviço remunerado à família com a qual reside.

- Situação de Trabalho - A situação de trabalho é definida como aquela em que o indivíduo tem um trabalho remunerado ou não-remunerado no período de referência, excetuando o trabalho excepcional.

- Tipo de empregado:

Estação Científica (UNIFAP)

ISSN 2179-1902
Empregado assalariado: é o indivíduo que tem vínculo empregatício caracterizado pela legislação trabalhista vigente, com ou sem carteira de trabalho assinada. Sua jornada de trabalho é prefixada pelo empregador e sua remuneração normalmente é fixa - sob a forma de salário, ordenado ou soldo que pode incluir adicionais de tempo de serviço, cargos de chefia, por insalubridade, periculosidade. Em alguns casos, essa remuneração pode ser composta de duas partes: uma fixa, prevista no contrato de trabalho, e outra variável, sob a forma de comissão que pode ser paga pelo empregador, cliente ou por ambos. Esta categoria inclui, também, o militar de carreira e o professor cujo salário é calculado por hora/aula, mas que tem um número predeterminado de aulas fixado pela escola;

Empregado que recebe exclusivamente em espécie/benefício: são os empregados que, em troca de seu trabalho, só recebem alojamento, alimentação, vestimenta ou outro tipo de remuneração em espécie ou benefício, como, por exemplo, servente de escola que recebe como pagamento pelos seus serviços os estudos para um filho;

Empregado que presta serviço militar obrigatório, assistencial ou religioso com alguma remuneração: são os indivíduos que prestam serviço militar obrigatório e os padres, freiras, pastores, etc. que recebem salário, bem como as pessoas que fazem algum tipo de serviço assistencial recebendo, por isso, uma remuneração em dinheiro;

Empregado que ganha exclusivamente por produção: é o trabalhador cujo vínculo empregatício é formalizado em contrato de autônomo, havendo apenas o compromisso de entregar a produção no prazo determinado. Portanto, só recebe pagamento por 
unidade ou produto ou serviço executado e não tem jornada de trabalho prefixada. 0 indivíduo nesta situação é classificado como autônomo para uma empresa;

Empregado doméstico: é o indivíduo que trabalha em casa de família contratado para realizar serviços domésticos. Tanto pode ser mensalista, diarista ou receber só em espécie/benefícios. O primeiro caso refere-se ao empregado que recebe salário mensal; o segundo, à pessoa que trabalha em casa de uma ou mais famílias recebendo remuneração por dia; o último, agrega o indivíduo que realiza trabalhos domésticos em casa de uma família tendo como pagamento por seus serviços apenas alimentação, alojamento, vestimenta ou outro tipo de remuneração em espécie ou benefício.

\section{CLASSES SOCIAIS NA RMS E SEUS ASPEC- TOS GERAIS}

Para melhor entendermos o perfil das classes sociais na RMS - visto que a renda familiar não retrata concretamente a realidade social - observaremos o universo delas por meio dos aspectos sócio-ocupacionais (nível de escolaridade, tipo de ocupação, grau de instrução do chefe de família, dentre outros). Desse modo, perceberemos que as famílias bem mais dotadas dos recursos que estão associados ao conceito de capital cultural - como elevado nível de escolaridade, por exemplo - são as que estão melhores situadas na pirâmide social. Dito isso, vale ressaltar que no sistema capitalista o capital cultural é de fundamental importância para assegurar às classes sociais importantes privilégios. Assim, a capacidade financeira que uma família tem em poder comprar o tempo dos seus filhos, para que estes possam dedicar-se plenamente aos estudos, permite às classes altas ocupar os melhores postos no mercado de trabalho. Enquanto as famílias da base da pirâmide, sobretudo as da ralé, em face de possuir exíguo capital cultural, estão fadadas a realizar tarefas braçais e de baixíssima qualificação técnica caso não hajam políticas sociais que visem equacionar o problema do ciclo geracional da pobreza.

\subsection{Mobilidade na estratificação social da RMS}

Diferentemente do que mostra os estudos afirmativos sobre a existência de uma nova classe média na RMS, onde pelo menos metade da população encontrar-se-ia na classe $C$, as informações aqui apresentadas com base no na PED de 2003 a 2010, evidenciam que esse percentual é apenas ligeiramente superior a $1 / 6$ da população. Além disso, os dados desta pesquisa nos mostram que, na média, o percentual de pessoas que estão no referido grupo social permaneceu quase inalterado ao longo desse período. Os dados mostram que mais da metade da população da RMS, desde 2003, é composta por famílias de classe $E$ (ou da ralé), visto que auferem renda mensal de 0 a 2 salários mínimos.

O grupo que ocupa o segundo lugar em termos de maior representatividade é os pobres, este que por sinal apresentou um comportamento bastante instável ao longo do período em questão. Já as classes B e A encolheram em termos percentuais, com maior destaque para a segunda. Esse fato evidencia duas coisas importantes: primeiro, o encolhimento das classes A e B nos mostra que houve um processo de retração da atividade econômica nos setores mais dinâmicos da economia na RMS, setores 
que inclusive requer maior qualificação técnica da sua força de trabalho e que concede maior remuneração aos trabalhadores nele empregados. Segundo, o encolhimento da classe Alta é indicativo de que um número bastante pequeno de famílias se apropria da renda gerada na região, fato que configura um processo de (re)concentração de renda na RMS (Gráfico 1).

Gráfico 1- Estratos de renda na RMS

Chart 1- Income strata in RMS

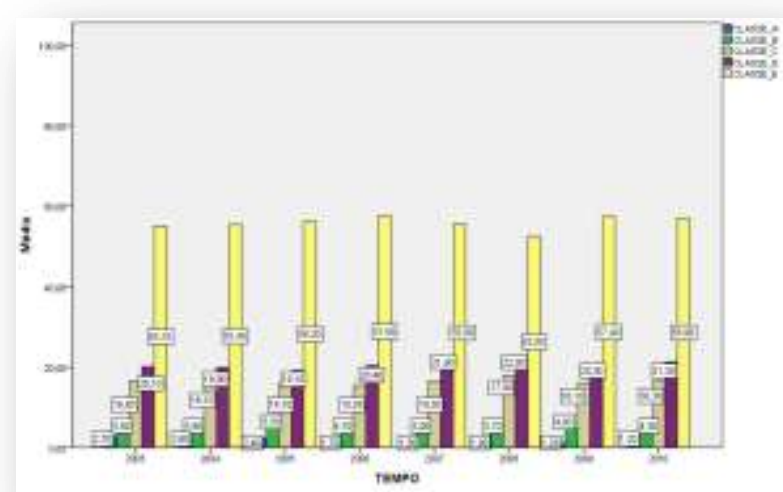

Fonte - Elaboração própria, Dados da PED, 2003 a 2010. Software spss 22

\subsection{Composição racial das classes socioe- conômicas na RMS}

Os dados da PED nos mostram que a Região Metropolitana de Salvador ainda continua conservando aspectos sociais de um recente passado de fortes contradições sociais, configurando-se, assim, como uma cidade onde os negros continuam tendo baixa representatividade social nas classes mais abonadas, além de sua participação nelas diminuir período após período, como pode ser visto na Tabela 1:
Tabela 1 - Composição racial da classe A

Table 1 - Racial composition of class A

\begin{tabular}{|c|r|r|c|}
\hline & BRANCOS & PARDOS & PRETOS \\
\hline 2003 & $37,8 \%$ & $54,1 \%$ & $8,1 \%$ \\
\hline 2004 & $38,7 \%$ & $55,5 \%$ & $5,9 \%$ \\
\hline 2005 & $40,7 \%$ & $51,8 \%$ & $7,5 \%$ \\
\hline 2006 & $39,1 \%$ & $53,9 \%$ & $6,9 \%$ \\
\hline 2007 & $38,8 \%$ & $52,3 \%$ & $8,9 \%$ \\
\hline 2008 & $43,3 \%$ & $50,1 \%$ & $6,2 \%$ \\
\hline 2009 & $43,5 \%$ & $50,4 \%$ & $6,2 \%$ \\
\hline 2010 & $42,4 \%$ & $53,6 \%$ & $4,0 \%$ \\
\hline
\end{tabular}

Fonte: Elaboração própria, com base nos dados da PED, 2003 a 2010

Além disso, o percentual de negros na classe $B$ também registrou queda no período em questão, tendo o percentual de brancos apresentado importante crescimento no período (crescimento de $4,6 \%$ no ano de 2010 em relação a 2003). Já o percentual de pardos apresentou pequeno decréscimo no ano de 2010 em relação a 2003 (Tabela 2).

Tabela 2 - Composição racial da classe B Table 2 - Racial composition of class B

\begin{tabular}{|c|c|c|c|}
\hline & BRANCOS & PARDOS & PRETOS \\
\hline 2003 & $29,2 \%$ & $59,3 \%$ & $11,4 \%$ \\
\hline 2004 & $27,7 \%$ & $61,3 \%$ & $10,9 \%$ \\
\hline 2005 & $30,7 \%$ & $57,9 \%$ & $11,3 \%$ \\
\hline 2006 & $29,0 \%$ & $61,0 \%$ & $9,8 \%$ \\
\hline 2007 & $34,1 \%$ & $53,9 \%$ & $12,0 \%$ \\
\hline 2008 & $35,5 \%$ & $52,8 \%$ & $11,7 \%$ \\
\hline 2009 & $34,1 \%$ & $56,0 \%$ & $9,9 \%$ \\
\hline 2010 & $29,3 \%$ & $62,3 \%$ & $8,4 \%$ \\
\hline
\end{tabular}

Fonte - Elaboração própria, com base nos dados da PED, 2003 a 2010

Já a classe C em 2010 era composta majoritariamente por pardos (65,3\%), seguido por negros $(16,45)$ e brancos $(18,3 \%)$, tendo os pardos um pequeno aumento percentual no período em questão, como pode ser observado na Tabela 3: 
Tabela 3 - Composição racial da classe $C$

Table 3 - Racial composition of class $C$

\begin{tabular}{|c|c|c|c|}
\hline & BRANCOS & PARDOS & PRETOS \\
\hline 2003 & $16,6 \%$ & $63,9 \%$ & $19,3 \%$ \\
\hline 2004 & $16,0 \%$ & $64,7 \%$ & $19,3 \%$ \\
\hline 2005 & $17,0 \%$ & $62,8 \%$ & $20,2 \%$ \\
\hline 2006 & $18,4 \%$ & $62,8 \%$ & $18,8 \%$ \\
\hline 2007 & $16,6 \%$ & $61,0 \%$ & $22,4 \%$ \\
\hline 2008 & $19,9 \%$ & $59,6 \%$ & $20,5 \%$ \\
\hline 2009 & $18,6 \%$ & $64,3 \%$ & $17,1 \%$ \\
\hline 2010 & $18,3 \%$ & $65,3 \%$ & $16,4 \%$ \\
\hline
\end{tabular}

Fonte: Elaboração própria, com base nos dados da PED, 2003 a 2010

A classe $D$ (os pobres) na RMS é também composta principalmente de pardos, sendo que o percentual desses registrou significativo aumento no ano de 2010 em relação a 2003 (aumento de 10,3\%). Em seguida estão os pretos $(18,0 \%)$, sendo que seu percentual apresentou significativo decréscimo no período supracitado (diminuição de $11,9 \%)$, seguida por brancos $(10,5 \%)$, como pode ser visto na Tabela 4:

Tabela 4 - Composição racial da classe D

Table 4 - Class D racial composition

\begin{tabular}{|c|c|c|c|}
\hline & BRANCOS & PARDOS & PRETOS \\
\hline 2003 & $9,0 \%$ & $61,1 \%$ & $29,9 \%$ \\
\hline 2004 & $8,4 \%$ & $63,8 \%$ & $27,8 \%$ \\
\hline 2005 & $9,9 \%$ & $61,2 \%$ & $28,8 \%$ \\
\hline 2006 & $9,9 \%$ & $63,0 \%$ & $27,1 \%$ \\
\hline 2007 & $9,9 \%$ & $62,6 \%$ & $27,5 \%$ \\
\hline 2008 & $11,0 \%$ & $62,3 \%$ & $26,7 \%$ \\
\hline 2009 & $9,9 \%$ & $67,0 \%$ & $23,1 \%$ \\
\hline 2010 & $10,5 \%$ & $71,4 \%$ & $18,0 \%$ \\
\hline
\end{tabular}

Fonte - Elaboração própria, com base nos dados da PED, 2003 a 2010

Na classe E o percentual de brancos é pequeno em relação aos demais grupos étnicos (era de apenas 9,6\% em 2010). Vale ressaltar que no ano de 2003 o percentual de negros que pertenciam a ralé era de $10,6 \%$, mas seu percentual diminuiu para $9,6 \%$ em 2010. Já o percentual de pardos é mais expressivo na classe $\mathrm{E}$ (era de $71,0 \%$ ), seguido pelos pretos (19,3\% em 2010). Ademais, podemos inferir com base nos da- dos da tabela 14 , que a ralé na RMS além de parda é também preta, e este fato nos mostra que a o fenômeno das desigualdades de classe é também um problema de racial (Tabela 5).

Tabela 5 - Composição racial da classe $\mathrm{E}$

Table 5 - Racial composition of class $E$

\begin{tabular}{|c|c|c|c|}
\hline & BRANCOS & PARDOS & PRETOS \\
\hline 2003 & $10,6 \%$ & $61,1 \%$ & $28,1 \%$ \\
\hline 2004 & $10,6 \%$ & $60,5 \%$ & $28,9 \%$ \\
\hline 2005 & $9,9 \%$ & $61,1 \%$ & $29,0 \%$ \\
\hline 2006 & $9,2 \%$ & $61,9 \%$ & $28,6 \%$ \\
\hline 2007 & $11,0 \%$ & $59,3 \%$ & $29,6 \%$ \\
\hline 2008 & $11,4 \%$ & $60,6 \%$ & $27,6 \%$ \\
\hline 2009 & $10,1 \%$ & $65,4 \%$ & $23,9 \%$ \\
\hline 2010 & $9,6 \%$ & $71,0 \%$ & $19,3 \%$ \\
\hline
\end{tabular}

Fonte - Elaboração própria, com base nos dados da PED, 2003 a 2010

\subsection{Setor de atividade por classes no mer- cado de trabalho da RMS}

Como se pode observar na Tabela 6, as classes socioeconômicas na RMS estão ocupados majoritariamente no setor de serviços. As classes A e B são as que apresentam o maior percentual da força de trabalho ocupada nesse setor, seguida pelas classes C, D e E, nessa ordem:

Tabela 6 - Ocupados no setor de serviços por classe Table 6 - Employed in the service sector by class

\begin{tabular}{|c|c|c|c|c|c|}
\hline & A & B & C & D & E \\
\hline 2003 & $70,00 \%$ & $68,60 \%$ & $65,2 \%$ & $57,0 \%$ & $54,9 \%$ \\
\hline 2004 & $72,80 \%$ & $71,10 \%$ & $65,9 \%$ & $55,8 \%$ & $55,1 \%$ \\
\hline 2005 & $74,10 \%$ & $69,60 \%$ & $66,2 \%$ & $56,3 \%$ & $54,4 \%$ \\
\hline 2006 & $71,80 \%$ & $71,90 \%$ & $66,3 \%$ & $57,3 \%$ & $54,1 \%$ \\
\hline 2007 & $74,70 \%$ & $73,30 \%$ & $66,6 \%$ & $57,9 \%$ & $54,5 \%$ \\
\hline 2008 & $73,60 \%$ & $74,30 \%$ & $66,5 \%$ & $58,9 \%$ & $55,0 \%$ \\
\hline 2009 & $71,10 \%$ & $73,80 \%$ & $67,8 \%$ & $58,1 \%$ & $55,5 \%$ \\
\hline 2010 & $73,00 \%$ & $75,00 \%$ & $66,9 \%$ & $57,4 \%$ & $55,7 \%$ \\
\hline
\end{tabular}

Fonte - Elaboração própria, com base nos dados da PED, 2003 a 2010

Sobre o setor de comércio, observa-se que é o setor onde está congregado o maior número de pessoas das classes $C, D$ e $E$, seguida pelo setor de serviços, como pode ser 
visto na Tabela 7:

Tabela 7 - Ocupados setor do comércio por classe

Table 7 - Occupied trade sector by class

\begin{tabular}{|c|c|c|c|c|c|}
\hline & A & B & C & D & E \\
\hline 2003 & $8,30 \%$ & $11,80 \%$ & $15,4 \%$ & $17,2 \%$ & $17,1 \%$ \\
\hline 2004 & $7,30 \%$ & $10,90 \%$ & $15,6 \%$ & $17,7 \%$ & $17,9 \%$ \\
\hline 2005 & $7,50 \%$ & $10,70 \%$ & $15,3 \%$ & $16,4 \%$ & $17,7 \%$ \\
\hline 2006 & $7,40 \%$ & $10,10 \%$ & $15,9 \%$ & $17,2 \%$ & $17,6 \%$ \\
\hline 2007 & $5,90 \%$ & $10,40 \%$ & $15,0 \%$ & $17,9 \%$ & $17,7 \%$ \\
\hline 2008 & $8,00 \%$ & $9,90 \%$ & $15,1 \%$ & $16,0 \%$ & $17,3 \%$ \\
\hline 2009 & $8,70 \%$ & $9,80 \%$ & $15,5 \%$ & $17,4 \%$ & $17,4 \%$ \\
\hline 2010 & $10,60 \%$ & $10,60 \%$ & $15,6 \%$ & $18,0 \%$ & $17,1 \%$ \\
\hline
\end{tabular}

Fonte - Elaboração própria, com base nos dados da PED, 2003 a 2010

No que tange ao setor industrial, entre 2003 a 2010, a taxa de participação da força de trabalho nesse setor oscilou bastante em todas as classes. Mas, em 2010 em relação a 2009, apenas a classe $C$ apresentou crescimento da força de trabalho no referido setor (Tabela 8):

Tabela 8 - Ocupados na indústria de transformação por classe Table 8 - Employed in manufacturing industry by class

\begin{tabular}{|c|c|c|c|c|c|}
\hline & A & B & C & D & E \\
\hline 2003 & $8,80 \%$ & $10,70 \%$ & $10,4 \%$ & $9,0 \%$ & $7,7 \%$ \\
\hline 2004 & $9,40 \%$ & $10,40 \%$ & $9,7 \%$ & $8,8 \%$ & $7,6 \%$ \\
\hline 2005 & $10,30 \%$ & $12,00 \%$ & $10,5 \%$ & $9,9 \%$ & $8,0 \%$ \\
\hline 2006 & $10,10 \%$ & $11,70 \%$ & $9,9 \%$ & $9,6 \%$ & $7,6 \%$ \\
\hline 2007 & $10,80 \%$ & $10,00 \%$ & $9,8 \%$ & $8,9 \%$ & $8,7 \%$ \\
\hline 2008 & $9,30 \%$ & $10,40 \%$ & $10,2 \%$ & $8,5 \%$ & $8,0 \%$ \\
\hline 2009 & $11,00 \%$ & $10,30 \%$ & $8,9 \%$ & $8,7 \%$ & $7,5 \%$ \\
\hline 2010 & $7,50 \%$ & $7,40 \%$ & $9,7 \%$ & $8,7 \%$ & $7,5 \%$ \\
\hline
\end{tabular}

Fonte - Elaboração própria, com base nos dados da PED, 2003 a 2010

Da força de trabalho ocupada na construção civil, as classes D e E são aquelas que apresentam maior contingente como pode ser visto na Tabela 9:
Tabela 9 - Ocupados no setor da construção civil por classe Table 9 - Employed in the civil construction sector by class

\begin{tabular}{|c|c|c|c|c|c|}
\hline & A & B & C & D & E \\
\hline 2003 & $2,60 \%$ & $2,10 \%$ & $3,3 \%$ & $6,0 \%$ & $5,7 \%$ \\
\hline 2004 & $2,61 \%$ & $2,20 \%$ & $3,0 \%$ & $5,6 \%$ & $5,3 \%$ \\
\hline 2005 & $1,40 \%$ & $2,30 \%$ & $3,1 \%$ & $5,9 \%$ & $5,5 \%$ \\
\hline 2006 & $1,41 \%$ & $2,00 \%$ & $3,2 \%$ & $5,7 \%$ & $6,5 \%$ \\
\hline 2007 & $2,40 \%$ & $2,41 \%$ & $3,8 \%$ & $5,7 \%$ & $6,6 \%$ \\
\hline 2008 & $3,40 \%$ & $2,50 \%$ & $3,9 \%$ & $6,5 \%$ & $7,1 \%$ \\
\hline 2009 & $3,10 \%$ & $2,60 \%$ & $4,4 \%$ & $6,8 \%$ & $8,0 \%$ \\
\hline 2010 & $3,40 \%$ & $3,90 \%$ & $4,2 \%$ & $8,0 \%$ & $8,8 \%$ \\
\hline
\end{tabular}

Fonte - Elaboração própria, com base nos dados da PED, 2003 a 2010

De 2003 a 2006 a taxa de participação da força de trabalho no setor da construção civil oscilou em todos os setores, passando a crescer de forma ininterrupta e em todas as classes a partir de então. A classe socioeconômica que registra maior participação da força de trabalho no referido setor é a classe $\mathrm{E}$, seguida pela classe $\mathrm{D}$.

\subsection{Níveis de escolaridade nas classes so- cioeconômicas}

Os dados da PED mostram que o nível de escolaridade na RMS aumentou consideravelmente nesses anos, em todos os estratos, principalmente nas classes socioeconômicas que compõe a base da pirâmide social, como é possível ver nas Tabelas $10 \mathrm{e}$ 11:

Tabela $10-1^{\circ}$ grau completo

Table 10 - Complete 1st grade

\begin{tabular}{|c|c|c|c|c|c|}
\hline & A & B & C & D & E \\
\hline 2003 & $21,5 \%$ & $25,5 \%$ & $39,0 \%$ & $57,0 \%$ & $58,0 \%$ \\
\hline 2004 & $18,8 \%$ & $24,1 \%$ & $37,9 \%$ & $55,6 \%$ & $57,0 \%$ \\
\hline 2005 & $16,4 \%$ & $22,8 \%$ & $36,9 \%$ & $52,5 \%$ & $56,7 \%$ \\
\hline 2006 & $17,1 \%$ & $19,9 \%$ & $33,0 \%$ & $50,5 \%$ & $54,4 \%$ \\
\hline 2007 & $14,7 \%$ & $19,8 \%$ & $33,4 \%$ & $48,3 \%$ & $52,4 \%$ \\
\hline 2008 & $11,7 \%$ & $19,0 \%$ & $31,5 \%$ & $46,3 \%$ & $52,5 \%$ \\
\hline 2009 & $9,6 \%$ & $16,9 \%$ & $28,5 \%$ & $44,8 \%$ & $59,1 \%$ \\
\hline 2010 & $10,0 \%$ & $16,8 \%$ & $26,9 \%$ & $43,1 \%$ & $48,8 \%$ \\
\hline
\end{tabular}

Fonte - Elaboração própria, com base nos dados da PED, 2003 a 2010 
Tabela $11-2^{\circ}$ grau completo

Table 11 - Complete 2st grade

\begin{tabular}{|c|c|c|c|c|c|}
\hline & A & B & C & D & E \\
\hline 2003 & $26,6 \%$ & $39,6 \%$ & $45,9 \%$ & $35,6 \%$ & $29,0 \%$ \\
\hline 2004 & $26,1 \%$ & $40,1 \%$ & $46,2 \%$ & $39,6 \%$ & $29,9 \%$ \\
\hline 2005 & $25,7 \%$ & $37,8 \%$ & $46,2 \%$ & $39,2 \%$ & $30,4 \%$ \\
\hline 2006 & $23,4 \%$ & $36,8 \%$ & $46,4 \%$ & $40,5 \%$ & $32,1 \%$ \\
\hline 2007 & $25,6 \%$ & $37,4 \%$ & $46,2 \%$ & $42,6 \%$ & $33,6 \%$ \\
\hline 2008 & $27,5 \%$ & $34,7 \%$ & $47,0 \%$ & $43,3 \%$ & $34,6 \%$ \\
\hline 2009 & $24,0 \%$ & $34,9 \%$ & $47,6 \%$ & $44,8 \%$ & $36,6 \%$ \\
\hline 2010 & $25,9 \%$ & $34,4 \%$ & $48,0 \%$ & $45,8 \%$ & $37,3 \%$ \\
\hline
\end{tabular}

Fonte - Elaboração própria, com base nos dados da PED, 2003 a 2010

Observa-se também que o número de pessoas que passaram a cursar o ensino superior na RMS apresentou um crescimento significativo ao longo desse período e em todos os estratos de renda. Porém, como é possível observar na Tabela 12, o maior de nível de escolarização ainda é um privilégio das classes mais abonadas:

Tabela $12-3^{\circ}$ grau completo

Table 12 - Complete 1st grade

\begin{tabular}{|c|c|c|c|c|c|}
\hline $\mathrm{A}$ & $\mathrm{B}$ & $\mathrm{C}$ & $\mathrm{D}$ & $\mathrm{E}$ & \\
\hline 2003 & $51,20 \%$ & $33,80 \%$ & $12,60 \%$ & $3,10 \%$ & $7,50 \%$ \\
\hline 2004 & $54,40 \%$ & $34,70 \%$ & $13,90 \%$ & $3,40 \%$ & $8,00 \%$ \\
\hline 2005 & $57,50 \%$ & $38,70 \%$ & $15,20 \%$ & $4,60 \%$ & $8,50 \%$ \\
\hline 2006 & $59,20 \%$ & $42,70 \%$ & $18,80 \%$ & $5,20 \%$ & $8,50 \%$ \\
\hline 2007 & $58,70 \%$ & $42,00 \%$ & $18,70 \%$ & $5,80 \%$ & $9,70 \%$ \\
\hline 2008 & $60,10 \%$ & $45,40 \%$ & $19,80 \%$ & $6,80 \%$ & $8,50 \%$ \\
\hline 2009 & $65,60 \%$ & $47,50 \%$ & $22,50 \%$ & $7,40 \%$ & $9,30 \%$ \\
\hline 2010 & $63,70 \%$ & $47,90 \%$ & $23,70 \%$ & $8,10 \%$ & $10,30 \%$ \\
\hline
\end{tabular}

Fonte - Elaboração própria, com base nos dados da PED, 2003 a 2010

\subsection{Chefes de família}

Na Região Metropolitana de Salvador, assim como em grande parte das regiões metropolitanas, o percentual de lares chefiados por mulheres aumentou em todas elas (Tabelas 13 e 14), ocorrendo com maior ênfase nos estratos composto por famílias de baixa renda.
Tabela 13 - Lares chefiados por homens

Table 13 - Men-headed households

\begin{tabular}{|c|c|c|c|c|c|}
\hline A & B & C & D & E & \\
\hline 2003 & $81,90 \%$ & $75,30 \%$ & $71,60 \%$ & $71,70 \%$ & $63,60 \%$ \\
\hline 2004 & $81,20 \%$ & $73,80 \%$ & $69,70 \%$ & $70,30 \%$ & $61,70 \%$ \\
\hline 2005 & $85,20 \%$ & $77,60 \%$ & $71,20 \%$ & $72,90 \%$ & $63,20 \%$ \\
\hline 2006 & $84,00 \%$ & $75,00 \%$ & $72,00 \%$ & $72,70 \%$ & $63,10 \%$ \\
\hline 2007 & $77,40 \%$ & $73,60 \%$ & $71,00 \%$ & $72,00 \%$ & $62,30 \%$ \\
\hline 2008 & $82,70 \%$ & $74,90 \%$ & $70,00 \%$ & $68,90 \%$ & $58,20 \%$ \\
\hline 2009 & $86,20 \%$ & $73,00 \%$ & $68,70 \%$ & $68,20 \%$ & $59,20 \%$ \\
\hline 2010 & $80,00 \%$ & $73,30 \%$ & $70,20 \%$ & $69,20 \%$ & $59,30 \%$ \\
\hline
\end{tabular}

Fonte - Elaboração própria, com base nos dados da PED, 2003 a 2010

Tabela 14 - Lares chefiados por mulheres Table 14 - Households headed by women

\begin{tabular}{|c|c|c|c|c|c|}
\hline & A & B & C & D & E \\
\hline 2003 & $18,1 \%$ & $24,7 \%$ & $28,4 \%$ & $28,3 \%$ & $36,4 \%$ \\
\hline 2004 & $18,8 \%$ & $26,2 \%$ & $30,3 \%$ & $29,7 \%$ & $38,3 \%$ \\
\hline 2005 & $14,8 \%$ & $22,4 \%$ & $28,8 \%$ & $27,1 \%$ & $36,8 \%$ \\
\hline 2006 & $16,0 \%$ & $24,1 \%$ & $28,0 \%$ & $27,3 \%$ & $36,9 \%$ \\
\hline 2007 & $22,6 \%$ & $26,4 \%$ & $29,0 \%$ & $28,0 \%$ & $37,7 \%$ \\
\hline 2008 & $17,3 \%$ & $25,1 \%$ & $30,0 \%$ & $31,1 \%$ & $41,8 \%$ \\
\hline 2009 & $13,8 \%$ & $27,0 \%$ & $31,3 \%$ & $31,8 \%$ & $40,8 \%$ \\
\hline 2010 & $20,0 \%$ & $26,7 \%$ & $29,8 \%$ & $30,8 \%$ & $40,7 \%$ \\
\hline
\end{tabular}

Fonte - Elaboração própria, com base nos dados da PED, 2003 a 2010

O crescimento do número de lares chefiados por mulheres na RMS está relacionado aos problemas sociais que os membros dessas classes estão mais expostos, como a violência urbana. Ademais, vale ressaltar que elas têm tido dificuldades de se inserir no mercado de trabalho, razão que as tem as levado exercer atividades por conta própria.

\subsection{Escolaridade do chefe de família}

Já os dados concernentes ao nível de educação fundamental dos chefes de família da RMS nos mostra que houve um importante processo de evolução em todas as classes, muito embora a quantidade de chefes de família que se encontram nas classes D e E com apenas o primeiro grau completo ainda seja bastante elevada, como pode ser observado na Tabela 15: 
Tabela 15 - Escolaridade do chefe de família (1ºrau completo) Table 15 - Schooling of the head of the family (1st Degree)

\begin{tabular}{|c|c|c|c|c|c|}
\hline & A & B & C & D & E \\
\hline 2003 & $8,00 \%$ & $14,50 \%$ & $32,00 \%$ & $53,30 \%$ & $54,70 \%$ \\
\hline 2004 & $5,20 \%$ & $13,10 \%$ & $32,40 \%$ & $51,00 \%$ & $53,30 \%$ \\
\hline 2005 & $4,60 \%$ & $13,30 \%$ & $31,00 \%$ & $47,70 \%$ & $54,10 \%$ \\
\hline 2006 & $5,10 \%$ & $11,60 \%$ & $27,50 \%$ & $47,00 \%$ & $51,30 \%$ \\
\hline 2007 & $6,00 \%$ & $11,70 \%$ & $29,60 \%$ & $44,00 \%$ & $49,40 \%$ \\
\hline 2008 & $6,80 \%$ & $10,20 \%$ & $27,10 \%$ & $41,30 \%$ & $49,70 \%$ \\
\hline 2009 & $3,30 \%$ & $10,00 \%$ & $23,30 \%$ & $40,60 \%$ & $46,90 \%$ \\
\hline 2010 & $4,90 \%$ & $9,50 \%$ & $22,70 \%$ & $38,30 \%$ & $46,40 \%$ \\
\hline
\end{tabular}

Fonte - Elaboração própria, com base nos dados da PED, 2003 a 2010

Evolução importante também foi registrada entre os chefes de família com nível médio de escolaridade em todas as classes (Tabela 16), com destaque para o movimento ocorrido no seio das classes $D$ e $E$, estas que apresentaram crescimento de $12,1 \%$ e $10,4 \%$, respectivamente.

Tabela 16 - Escolaridade do chefe de família ( $2^{\circ} \mathrm{grau}$ completo) Table 16 - Head of household education (2nd grade)

\begin{tabular}{|c|c|c|c|c|c|}
\hline $\mathrm{A}$ & $\mathrm{B}$ & $\mathrm{C}$ & $\mathrm{D}$ & $\mathrm{E}$ & \\
\hline 2003 & $25,20 \%$ & $39,60 \%$ & $46,70 \%$ & $35,80 \%$ & $28,40 \%$ \\
\hline 2004 & $24,50 \%$ & $40,10 \%$ & $45,90 \%$ & $37,90 \%$ & $29,40 \%$ \\
\hline 2005 & $23,00 \%$ & $36,80 \%$ & $46,10 \%$ & $40,80 \%$ & $29,60 \%$ \\
\hline 2006 & $22,90 \%$ & $36,50 \%$ & $48,30 \%$ & $40,90 \%$ & $31,90 \%$ \\
\hline 2007 & $28,60 \%$ & $39,00 \%$ & $46,20 \%$ & $43,80 \%$ & $34,10 \%$ \\
\hline 2008 & $24,10 \%$ & $35,80 \%$ & $48,10 \%$ & $45,10 \%$ & $35,20 \%$ \\
\hline 2009 & $25,70 \%$ & $38,40 \%$ & $49,70 \%$ & $47,00 \%$ & $37,70 \%$ \\
\hline 2010 & $26,50 \%$ & $37,40 \%$ & $48,80 \%$ & $48,10 \%$ & $38,80 \%$ \\
\hline
\end{tabular}

Fonte - Elaboração própria, com base nos dados da PED, 2003 a 2010

Os dados da PED ainda nos mostra que houve um importante processo de crescimento na taxa de chefes de família que passaram a ter nível superior (Tabela 17), sendo que esse processo mais intenso nas classes B, C e D quando comparado o primeiro ano com o último da série em questão.
Tabela 17- Escolaridade do chefe de família ( $3^{\circ}$ grau completo) Table 17- Head of household education (3rd grade)

\begin{tabular}{|c|c|c|c|c|c|}
\hline A & B & C & D & E & \\
\hline 2003 & $68,50 \%$ & $45,50 \%$ & $18,80 \%$ & $4,40 \%$ & $8,20 \%$ \\
\hline 2004 & $69,90 \%$ & $46,40 \%$ & $19,70 \%$ & $5,00 \%$ & $8,60 \%$ \\
\hline 2005 & $72,40 \%$ & $49,50 \%$ & $21,00 \%$ & $5,30 \%$ & $9,10 \%$ \\
\hline 2006 & $72,00 \%$ & $51,60 \%$ & $22,80 \%$ & $6,80 \%$ & $9,50 \%$ \\
\hline 2007 & $65,50 \%$ & $49,00 \%$ & $22,80 \%$ & $7,50 \%$ & $9,60 \%$ \\
\hline 2008 & $69,10 \%$ & $53,60 \%$ & $22,90 \%$ & $8,40 \%$ & $8,30 \%$ \\
\hline 2009 & $71,00 \%$ & $51,30 \%$ & $25,30 \%$ & $8,00 \%$ & $8,70 \%$ \\
\hline 2010 & $68,10 \%$ & $52,10 \%$ & $27,10 \%$ & $9,70 \%$ & $9,20 \%$ \\
\hline
\end{tabular}

Fonte - Elaboração própria, com base nos dados da PED, 2003 a 2010

\section{CONSIDERAÇÕES FINAIS}

A Região Metropolitana de Salvador apresentou melhorias significativas em muitos aspectos sociais. Apesar de ter ocorridos tais avanços, a RMS ainda conserva antigos problemas de um passado não muito distante. O contingente de miseráveis, por exemplo, continua elevado, visto que mais de 26\% da população em 2010 sobrevivia com apenas meio salário mínimo. Ademais, observou-se também que o número de lares chefiados por mulheres nas classes da base da pirâmide cresceu sistematicamente e o grau de escolaridade dos chefes de família nessas classes embora tenha aumentado ainda continua muito baixo, fato que nos leva inferir que estas classes tenderão a reproduzir o ciclo geracional da pobreza, por conta do parco capital cultural que detém.

Ademais, a representatividade dos negros nas classes mais abastadas ainda continua pouco expressiva, além de ter diminuído em 2010 em comparação a 2003. Diante do exposto, as classes mais aquinhoadas da Região Metropolitana de Salvador continuam sendo composta basicamente de brancos e mestiços, mostrando com isso que a desigualdade entre as classes na RMS é também um fenômeno de cor. Um fato 
também que chama a atenção nesse processo é a diminuição de trabalhadores ocupados no setor industrial e aumento nos demais setores (comércio, serviços e construção civil). Assim, pode-se perceber que a maioria das vagas criadas nesse processo se caracterizou pela exigência de baixa qualificação técnica, o que é coerente com expansão de empregos no setor de comércio e serviços basicamente.

$\mathrm{Na}$ Região Metropolitana de Salvador, onde metade da população é da classe $C$, este grupo social na referida região era de apenas $16 \%$ em 2010. Esse percentual, inclusive, permaneceu relativamente imóvel entre 2003 e 2010, ou seja, quase não apresentou alterações. Nesse processo, observou-se também que houve um encolhimento do tamanho das classes A e B na RMS, sendo a ocorrência desse processo mais intensa na primeira. Tal fato, como já foi dito, está diretamente relacionado à diminuição dos postos de trabalho gerados no setor industrial, este que é responsável pela geração de empregos de maiores remunerações. Além disso, pôde-se observar que a maior parte da população na referida região ainda é estão nas classes $D$ e $E$, não na classe $C$ (ou classe batalhadora) como tem sugeridos outros estudos. Assim, pode-se afirmar que o processo de mobilidade social ocorrido na pirâmide social na Região Metropolitana de Salvador foi praticamente estático no período em questão a despeito dos avanços sociais ocorridos. Desse modo, a RMS se apresenta como uma atipia em relação ao próprio Brasil, pois as mudanças ocorridas no período em questão não foram suficientes para promover um processo pleno de mobilidade social dos pobres.

\section{REFERÊNCIAS}

CASTRO, N.; BARRETO, V. S. Trabalho e desigualdades raciais. Negros e Brancos no mercado de trabalho de Salvador. Salvador: Anablume, 1998. 228 p.

DIEESE. A situação do trabalho no Brasil na primeira década dos anos 2000. São Paulo, 2012, 404 p.

GIL, A. C. Métodos e técnicas de pesquisa

social. São Paulo: Atlas, 2008. 199 p.

GUERRA, A. et al. Classe média desenvol-

vimento e crise. São Paulo: Cortez, 2006.

$143 \mathrm{p}$.

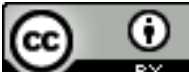
access article distributed under the terms of the Creative Commons Attribution License, which permits unrestricted use, distribution, and reproduction in any medium, provided the original work is properly cited.

Artigo recebido em 14 de dezembro de 2016.

Avaliado em 10 de janeiro de 2017.

Aceito em 18 de janeiro de 2017.

Publicado em 28 de março de 2017.

\section{Como citar este artigo (ABNT):}

OLIVEIRA, Ualace Roberto de Jesus. Classes sociais e classes socioeconômicas: um estudo sobre os estratos sociais na Região Metropolitana de Salvador entre 2003 a 2010. Estação Científica (UNIFAP), Macapá, v. 6, n. 3, p. 85-96, set./dez. 2016. 